\title{
High degree of multiple paternity in the viviparous Shiner Perch, Cymatogaster aggregata, a fish with long-term female sperm storage
}

\author{
Jin-Xian Liu • John C. Avise
}

Received: 9 November 2010/Accepted: 22 December 2010/Published online: 11 January 2011

(C) The Author(s) 2011. This article is published with open access at Springerlink.com

\begin{abstract}
The Shiner Perch (Cymatogaster aggregata Gibbons) exhibits a viviparous reproductive mode and longterm female sperm storage, two biological features that may predispose this fish species for both intense sperm competition and frequent multiple paternity within broods. To test these hypotheses, we used polymorphic microsatellite markers to identify sires and quantify paternal contributions to the progeny arrays of 27 pregnant females from a natural population of $C$. aggregata. The number of sires per brood ranged from one to eight (mean 4.6), typically with skewed distributions of fertilization success by the fathers but no correlation between sire number and brood size. The extraordinarily high incidences of multiple paternity in this species probably are due in part to high rates of mate encounter, but selection pressures related to the avoidance of maternal-fetal incompatibility may further have promoted the evolution of polyandrous mating behaviors in this femalepregnant species. Our genetic data are consistent with the hypothesis that viviparity, long-term sperm storage, and extreme polyandry are interrelated reproductive phenomena that should promote the evolution of post-copulatory sperm competition and/or cryptic female choice in these fishes.
\end{abstract}

\section{Introduction}

Despite the potential risks and costs associated with copulation, multiple mating by females (polyandry) is a

Communicated by T. Reusch.

J.-X. Liu $(\bowtie)$ - J. C. Avise

Department of Ecology and Evolutionary Biology,

University of California, Irvine, CA 92697, USA

e-mail: jinxianliu@gmail.com taxonomically widespread phenomenon (Birkhead and Møller 1998; Avise et al. 2002; Griffith et al. 2002; Stockley 2003; Uller and Olsson 2008), the adaptive significance of which is currently under considerable debate (Simmons 2005; Uller and Olsson 2008). Several hypotheses have been advanced to explain the evolution of polyandry, and these are usually divided into direct material benefits and indirect genetic benefits. Direct benefits to polyandrous females include fertilization assurance, nutrient acquisition through courtship, and reduced risk of sexual harassment (Birkhead and Pizzari 2002). Indirect genetic benefits also might arise by any of several routes (Jennions and Petrie 2000; Birkhead and Pizzari 2002). When gametes from two or more males actively vie for fertilizations of ova (Parker 1998; Birkhead and Pizzari 2002), sperm competition should ensure that a polyandrous female's eggs are fertilized by genetically robust cells that might also enhance offspring viability and/or increase the odds that sons will produce competitive sperm (Curtsinger 1991; Keller and Reeve 1995). Furthermore, when a polyandrous female fertilizes her ova via "cryptic female choice", the consequence might be an increase in the genetic quality of her offspring and/or a reduced risk of fertilization by genetically incompatible sperm (Zeh and Zeh 1996, 1997; Jennions and Petrie 2000; Tregenza and Wedell 2000; Birkhead and Pizzari 2002). Finally, high genetic diversity among the progeny of a polyandrous female might serve to buffer her brood against unpredictable environmental fluctuations (Yasui 1998, 2001).

Sperm competition and cryptic female choice may be especially important in species in which females can store viable sperm for long periods of time (Birkhead and Møller 1993). A long interval between copulation and fertilization may enhance opportunities for sperm competition as well as facilitate the evolution of mechanisms that might permit a 
polyandrous female to exercise post-copulatory control over her utilization of sperm from different sexual partners (Birkhead and Møller 1993). Furthermore, reproductive mode can have a critical impact on forces underlying the evolution of polyandry (Zeh and Zeh 2000, 2001). For example, suppose that multiple mating and multiple paternity help a polyandrous female to protect her reproductive investment against the threat of incompatibility between maternal and paternal genomes (Zeh and Zeh 1996, 1997). Then, due to intimate maternal-fetal interactions, such avoidance of genetic incompatibility may be much more important for females in viviparous than in oviparous species (Zeh and Zeh 2001).

Surfperches (Embiotocidae) are viviparous teleost fishes that inhabit coastal waters of the North Pacific (Tarp 1952; DeMartini 1969). Viviparity in the family is highly developed, with progeny being born in an almost adult condition (Baltz 1984). The natural history of the Shiner Perch Cymatogaster aggregata Gibbons, a small embiotocid of coastal waters from southern Alaska to Baja California (DeMartini 1969), has been studied extensively. Shoals of females enter shallow waters in the spring and summer to give birth to broods of large, well-developed embryos (Eigenmann 1892; Turner 1938; Wiebe 1968). Copulations take place soon after parturition and are confined to a short period of time (ca. 2 months after parturition). Both females and males show elaborate courtship and mating behaviors (Hubbs 1917; Wiebe 1968; Shaw and Allen 1977). During each reproductive season, the male's anal fin develops a complex system of appendages and tubular structures used for sperm transfer (Wiebe 1968). Each male courts only females of his own size group, and intermale aggression is strongly size-assortative (DeMartini 1988). The average testis size is relatively large (Wiebe 1968; DeMartini 1988). Dense aggregations of sperm are introduced into the female reproductive tract via spermatophore packages, which rapidly dissolve and release sperm after copulation (Gardiner 1978a). Inside the female, the sperm are maintained within pockets in the ovarian epithelium (Gardiner 1978b) for about 6 months before ovulation and fertilization take place in December (Eigenmann 1892; Turner 1938; Wiebe 1968). The metabolic systems of the stored sperm are influenced by environmental conditions inside the ovarian lumen (Gardiner 1978c). Fertilization is accomplished by the penetration of sperm through the epithelium of an ovigerous fold covering the mature eggs, and the fertilized eggs are evacuated into the ovarian cavity (Eigenmann 1892; Turner 1938). Sperm are found in the intestinal tract of the developing embryos, and are possibly used as nutrient (Eigenmann 1892). Embryos are retained within the ovarian compartments where they absorb nutritive materials and oxygen from ovarian fluid through modifications that occur in the developing embryos and ovary (Eigenmann 1892; Turner 1938; deVlaming et al. 1983).
Brood size is rather small, with a large three-year-old female perhaps giving birth to as many as 30 young, each about $30 \mathrm{~mm}$ in length (Eigenmann 1892; Turner 1938). Young-ofthe-year males become sexually mature within a short period of time during the first summer (Shaw 1971). Some aspects of sexual dimorphism in various surfperch species, including early maturity as well as reduced growth and survival of males, may be among the evolutionary consequences of selection pressures related to sperm competition and sperm storage (Warner and Harlan 1982).

Long-term sperm storage, mixing of sperm in the ovary, and relatively large testis sizes all suggest a high intensity of sperm competition in $C$. aggregata. Considering the species' high potential for sperm competition and its advanced viviparous reproductive mode, we postulated that Shiner Perch might show exceptionally high degrees of multiple paternity. Furthermore, if post-copulatory paternity-biasing mechanisms (sperm competition or cryptic female choice) are at play in this species, we might expect strong evidence for unequal reproductive contributions by different sires of a brood. Previously, multiple paternity was documented in only 42 among 446 surveyed broods $(9.4 \%)$ in C. aggregata from three populations (Darling et al. 1980), but the limited variability of allozyme markers in that earlier genetic study precluded firmer conclusions about biological parentage. Indeed, highly variable microsatellite loci later were used to uncover much higher rates of multiple paternity in two other surfperch species: Embiotoca jacksoni and E. lateralis (Reisser et al. 2009).

The goal of this study is to assess the potential effect of sperm competition and/or female cryptic choice on patterns of multiple paternity in the viviparous $C$. aggregata with long-term sperm storage. Specifically, novel microsatellite loci were cloned and characterized from this species and were applied to parentage analysis of field-collected broods. This study allowed us to address three main questions: (a) What are the frequency and degree of multiple paternity in this species? (b) How much reproductive skew exists among the sires of a brood? and c) How do patterns of multiple paternity in this species compare to those of other female-pregnant fishes?

\section{Materials and methods}

\section{Sample collection}

In March 2010, adult males and gravid females of C. aggregata were collected near a shallow rock jetty at the mouth of Newport Bay, Orange County, California (latitude $33^{\circ} 35^{\prime} 31^{\prime \prime} \mathrm{N}$; longitude $\left.117^{\circ} 52^{\prime} 40^{\prime \prime} \mathrm{W}\right)$. Standard length was measured for each female, and ovaries were dissected and embryos counted. Fin clips of adults and 
whole embryos were preserved in a saline solution $(20 \%$ dimethyl sulfoxide, 0.25 EDTA, saturated with $\mathrm{NaCl}, \mathrm{pH}$ 8.0) (Seutin et al. 1991) for DNA analysis.

Microsatellite development

Microsatellites were isolated from a single specimen of C. aggregata following an enrichment protocol described by Hamilton et al. (1999) and modified by Hauswaldt and Glenn (2003). Primers flanking the microsatellite repeat regions were designed using Primer Premier version 5.00 (PREMIER Biosoft International). Primers were optimized and checked for polymorphisms using a sample of 36 adults. Observed and expected heterozygosities were calculated, and deviations from Hardy-Weinberg equilibrium were examined using an exact test based on a Markov Chain method (Guo and Thompson 1992) for each locus. The presence of genotypic disequilibrium between all pairs of loci was tested using the likelihood ratio test. All analyses were conducted by using Arlequin version 2.0 (Schneider et al. 2000). Expected exclusion probabilities (Dodds et al. 1996) for each locus and across all loci were calculated with GERUD 2.0 (Jones 2005). The presence of null alleles for each locus was checked using Micro-Checker ver. 2.2.3 (Van Oosterhout et al. 2004). A total of six highly polymorphic dinucleotide loci were chosen for this study.

\section{Microsatellite genotyping}

Genomic DNA was extracted from fin clips of adults and posterior parts of embryos using a proteinase $\mathrm{K}$ digestion and phenol/chloroform/isoamyl extraction procedure (Milligan 1998). Tailed PCR was used to produce fluorescently labeled DNA fragments (Boutin-Ganache et al. 2001). M13 reverse (5'-GGAAACAGCTATGACCAT- $3^{\prime}$ ) was added to the $5^{\prime}$ end of one primer in each pair. An M13 reverse primer that is fluorescently labeled (FAM, HEX, or NED) was included in the PCR, resulting in a labeled product for detection. All loci were amplified separately on a Mastercycler (Eppendorf) in a $10-\mu$ l reaction containing about $50 \mathrm{ng}$ genomic DNA, $2 \mu \mathrm{l}$ of $5 \times$ buffer (Promega, Madison, WI), $0.2 \mathrm{mM}$ of each dNTP, $0.2 \mu \mathrm{M}$ labeled M13 reverse primer and locus specific primer without tail, $0.02 \mu \mathrm{M}$ locus specific primer with M13 reverse tail, and 0.25 U Taq DNA polymerase (Promega, Madison, WI). Thermal cycling parameters for all amplifications were as follows: $95^{\circ} \mathrm{C}$ for $3 \mathrm{~min}$, then 35 cycles each at $95^{\circ} \mathrm{C}$ for $20 \mathrm{~s}, 52^{\circ} \mathrm{C}$ for $20 \mathrm{~s}$, and $72^{\circ}$ for $30 \mathrm{~s}$, followed by 1 cycle of final elongation at $72^{\circ} \mathrm{C}$ for $10 \mathrm{~min}$. Amplified products were pooled and diluted 15 to 20 -fold, and $1 \mu \mathrm{l}$ of the pool was mixed with $10 \mu \mathrm{l}$ of deionized formamide and $0.3 \mu \mathrm{l}$ of GS500 size standard (Applied Biosystems, Foster City, CA). Samples were denatured for $4 \mathrm{~min}$ at $95^{\circ} \mathrm{C}$ and electrophoresed on an ABI PRISM 3100xl DNA analyzer. Allele scoring was performed using GENEMAPPER software version 4.0 (Applied Biosystems, Foster City, CA). Scoring was repeated for 30 random individuals at all six loci to estimate scoring error (but identical genotypes were obtained for all replicates).

\section{Paternity and statistical analysis}

Because our data set exceeded the maximum numbers of sires set by GERUD 2.0 (six), this software was not used for paternity analysis. Paternity inference was conducted using COLONY 2.0, which implements a maximum likelihood method that takes into account maternal information and estimated allele frequencies in the population (Wang 2004; Wang and Santure 2009; Jones and Wang 2010). COLONY evaluates genetic parentage by partitioning offspring into full-sib groups according to likelihood scores assuming Mendelian segregation and no maximum limit on the numbers of contributing parents. The configuration with maximum likelihood is searched by a simulated annealing algorithm. Thus, the number of sires contributing to each female's broods and the reproductive skew among males could be determined. The degree of reproductive skew was measured by the binomial skew index $B$, which is based on the observed variance among sires corrected by the expected binomial variance if all sires had an equal probability of contributing to the brood (Nonacs 2000). A value of zero implies a random distribution of offspring among sires, positive values indicate skew, and significant negative values imply an overly equal distribution of offspring. Significance levels of $B$ were estimated by simulation with 10,000 permutations. All of the skew analyses were conducted by SKEW CALCULATOR 2003 (http:// www.eeb.ucla.edu/Faculty/Nonacs/shareware.htm). A test for a correlation between brood size and female standard length was performed. To assess whether larger broods were more likely to contain offspring from each of the males with whom a female had mated, a linear regression test for correlation between brood size and the number of sires was performed.

\section{Results}

Population characterization

A total of 27 pregnant females and 9 males, with standard lengths ranging from $97 \mathrm{~mm}$ to $127 \mathrm{~mm}$, were collected. Average brood size was 12.9 individuals (ranging from 7 to 22 across the 27 broods). Stages of gestation varied among broods, but within a brood there was little range in the stage of embryonic development. Brood size was positively 
correlated with female standard length $\left(r^{2}=0.65, d f=26\right.$, $P<0.001)$.

Microsatellite markers

All six dinucleotide microsatellite loci were highly variable, displaying from 15 to 28 alleles per locus (Table 1). Observed and expected heterozygosities were high for all loci and ranged from 0.94 to 1.00 (Table 1). No evidence of genotypic disequilibrium between loci was detected, and all loci were in Hardy-Weinberg equilibrium. These loci were extremely informative for parentage analysis, with expected exclusion probabilities (under the one-parentknown model) ranging from 0.79 to 0.91 for each locus and $>0.999$ for all six loci combined (Table 1). Microchecker did not find any evidence for the presence of null alleles at any locus.

Genetic paternity

Genotypes at six microsatellite loci were determined for 36 adults and a total of 348 embryos. No null alleles or maternally derived de novo mutations were detected. For each brood, the best (maximum likelihood) inferred configuration consisting of full-sib families is shown in Table 2. Multiple paternity was detected in $26(96 \%)$ of the 27 broods. The number of sires per brood ranged from one to a maximum of eight, with an average of 4.6 sires per brood (Table 2; Fig. 1). Of the 26 multiply sired broods, eight $(31 \%)$ were significantly skewed from equal paternal contributions (Table 2; Fig. 2). The number of sires per brood was not significantly correlated with brood size $\left(r^{2}=0.007, d f=26, P=0.66\right)$. None of the nine collected males matched any of the genetically inferred sires.

\section{Discussion}

Our microsatellite analyses demonstrate a high incidence of multiple paternity in C. aggregata. Of the 27 broods analyzed, 26 proved to have been sired by more than one male. The frequency of multiple paternity in C. aggregata $(96 \%)$ is thus among the highest reported for internally fertilizing vertebrates (Uller and Olsson 2008; Avise and Liu 2010; Soulsbury 2010) and is much higher than the previous estimate (9\%) for this species based on allozyme markers that were far less polymorphic (Darling et al. 1980). Microsatellite loci similarly have indicated high rates of multiple paternity (100\% for both species) within the broods of two other embiotocid species: the Black Surfperch Embiotoca jacksoni and the Striped Surfperch E. lateralis (Reisser et al. 2009). All of these genetic analyses based on microsatellite markers thus indicate that polyandry must be an extremely common phenomenon in surfperches. Furthermore, we detected an average of 4.6 sires per brood in $C$. aggregata, a value that is even higher $(P<0.05$, one tailed t-test $)$ than the means of about 3.5 sires per brood for both $E$. jacksoni and E. laterali (Reisser et al. 2009). All of these values place surfperches among the highest-ranked internally fertilizing vertebrate groups in terms of the overall magnitude of genetically documented multiple mating by females (Uller and Olsson 2008; Avise and Liu 2010).

Higher mean number of sires per brood in C. aggregata than in other embiotocids is consistent with more intense sperm competition in C. aggregata, and with the fact that

Table 1 Characteristics of six microsatellite loci in a sample of 36 adult individuals of Shiner Perch

\begin{tabular}{|c|c|c|c|c|c|c|c|}
\hline Locus & Repeat motif & Primer sequences & Size range & $\begin{array}{l}\text { Number of } \\
\text { alleles }\end{array}$ & Ho & $\mathrm{He}$ & $\begin{array}{l}\text { Exclusion } \\
\text { probability }\end{array}$ \\
\hline Cagg15 & $(\mathrm{AC})_{25}$ & $\begin{array}{l}\text { *F: Fam-TAGCACATTAGGATTCAAAA } \\
\text { R: ATTAGAGCAGGGTAGGATTA }\end{array}$ & $205-263$ & 22 & 0.972 & 0.951 & 0.875 \\
\hline Cagg27 & $(\mathrm{GT})_{28}$ & $\begin{array}{l}\text { *F: Hex-GAAACATAATAAACAGCAGGAT } \\
\text { R: GAAGGAGATGAAAGGAACAA }\end{array}$ & $218-288$ & 22 & 0.944 & 0.919 & 0.816 \\
\hline Cagg28 & $(\mathrm{AC})_{19}$ & $\begin{array}{l}\text { *F: Ned-CATACCGATGTTTAGACAGAA } \\
\text { R: ACAAATGGCAGTGAAAGGAG }\end{array}$ & $251-292$ & 22 & 1.000 & 0.949 & 0.870 \\
\hline Cagg29 & $(\mathrm{AC})_{35}$ & $\begin{array}{l}\text { *F: Ned-ACAAGGACACCTGTCTCAAC } \\
\text { R: GAACTAACTCTTCCAGCAAA }\end{array}$ & $166-258$ & 28 & 0.972 & 0.967 & 0.906 \\
\hline Cagg36 & $(\mathrm{GT})_{20}$ & $\begin{array}{l}\text { *F: Hex-GCAAGTTGGCATGTGATGAG } \\
\text { R: GCCTGGCAGATGTGAAAGAG }\end{array}$ & $104-142$ & 15 & 0.944 & 0.910 & 0.794 \\
\hline Cagg50 & $(\mathrm{GT})_{36}$ & $\begin{array}{l}\text { *F: Fam-CGTGCAGACGGAAATGTGAT } \\
\text { R: ACCTGCTTCTTTCAGGGACA }\end{array}$ & $123-217$ & 26 & 0.972 & 0.959 & 0.890 \\
\hline
\end{tabular}

* The complete sequence of the primer includes M13 reverse tail ( $5^{\prime}$-GGAAACAGCTATGACCATG- $\left.3^{\prime}\right)$ at its $5^{\prime}$-end. M13 reverse oligo labeled with Fam, Hex, or Ned was used in the PCR reaction 
Table 2 Multiple mating for 27 broods of Shiner Perch from Newport Bay

\begin{tabular}{|c|c|c|c|c|c|c|c|c|c|c|c|c|c|}
\hline Family & $\begin{array}{l}\text { Brood } \\
\text { size }(n)\end{array}$ & $\begin{array}{l}\text { Standard } \\
\text { length }(\mathrm{mm})\end{array}$ & $\begin{array}{l}\text { Number of } \\
\text { sires }\end{array}$ & Sire 1 & Sire 2 & Sire 3 & Sire4 & Sire 5 & Sire 6 & Sire 7 & Sire 8 & $B$ value & $P$ \\
\hline SP01 & 12 & 108 & 2 & 8 & 4 & & & & & & & 0.014 & 0.382 \\
\hline SP02 & 13 & 112 & 5 & 7 & 3 & 1 & 1 & 1 & & & & 0.099 & 0.035 \\
\hline SP03 & 11 & 111 & 5 & 6 & 2 & 1 & 1 & 1 & & & & 0.083 & 0.087 \\
\hline SP04 & 13 & 115 & 4 & 5 & 4 & 3 & 1 & & & & & -0.006 & 0.511 \\
\hline SP05 & 16 & 114 & 6 & 7 & 3 & 2 & 2 & 1 & 1 & & & 0.047 & 0.097 \\
\hline SP06 & 14 & 111 & 8 & 5 & 2 & 2 & 1 & 1 & 1 & 1 & 1 & 0.006 & 0.375 \\
\hline SP07 & 13 & 101 & 4 & 7 & 4 & 1 & 1 & & & & & 0.089 & 0.053 \\
\hline SP08 & 12 & 106 & 2 & 10 & 2 & & & & & & & 0.181 & 0.038 \\
\hline SP09 & 14 & 112 & 2 & 13 & 1 & & & & & & & 0.332 & 0.003 \\
\hline SP10 & 13 & 111 & 5 & 5 & 3 & 3 & 1 & 1 & & & & 0.005 & 0.408 \\
\hline SP11 & 9 & 98 & 6 & 3 & 2 & 1 & 1 & 1 & 1 & & & -0.049 & 0.910 \\
\hline SP12 & 12 & 108 & 7 & 5 & 2 & 1 & 1 & 1 & 1 & 1 & & 0.022 & 0.219 \\
\hline SP13 & 15 & 121 & 6 & 8 & 2 & 2 & 1 & 1 & 1 & & & 0.111 & 0.008 \\
\hline SP14 & 14 & 114 & 6 & 5 & 3 & 3 & 1 & 1 & 1 & & & 0.009 & 0.387 \\
\hline SP15 & 11 & 103 & 6 & 4 & 2 & 2 & 1 & 1 & 1 & & & -0.019 & 0.623 \\
\hline SP16 & 12 & 117 & 4 & 8 & 2 & 1 & 1 & & & & & 0.174 & 0.010 \\
\hline SP17 & 22 & 127 & 4 & 14 & 6 & 1 & 1 & & & & & 0.199 & 0.000 \\
\hline SP18 & 15 & 115 & 2 & 14 & 1 & & & & & & & 0.342 & 0.001 \\
\hline SP19 & 11 & 104 & 1 & 11 & & & & & & & & $N A$ & $N A$ \\
\hline SP20 & 12 & 112 & 7 & 5 & 2 & 1 & 1 & 1 & 1 & 1 & & 0.022 & 0.211 \\
\hline SP21 & 13 & 108 & 2 & 11 & 2 & & & & & & & 0.201 & 0.021 \\
\hline SP22 & 12 & 114 & 4 & 7 & 2 & 2 & 1 & & & & & 0.090 & 0.065 \\
\hline SP23 & 12 & 104 & 5 & 4 & 3 & 2 & 2 & 1 & & & & -0.031 & 0.805 \\
\hline SP24 & 13 & 113 & 8 & 3 & 2 & 2 & 2 & 1 & 1 & 1 & 1 & -0.044 & 0.981 \\
\hline SP25 & 7 & 97 & 2 & 5 & 2 & & & & & & & 0.020 & 0.458 \\
\hline SP26 & 12 & 114 & 7 & 3 & 3 & 2 & 1 & 1 & 1 & 1 & & -0.036 & 0.847 \\
\hline SP27 & 15 & 117 & 5 & 7 & 3 & 3 & 1 & 1 & & & & 0.053 & 0.099 \\
\hline
\end{tabular}

Brood size $(n)$, standard length, number of sires, and number of offsprings sired by up to eight putative males as calculated by COLONY version 2.0.1.1 (Wang 2004) are provided. The binomial skew index $B$ and corresponding $P$ values are also indicated

Fig. 1 Microsatellite parentage analysis of 27 broods of Shiner Perch, Cymatogaster aggregata

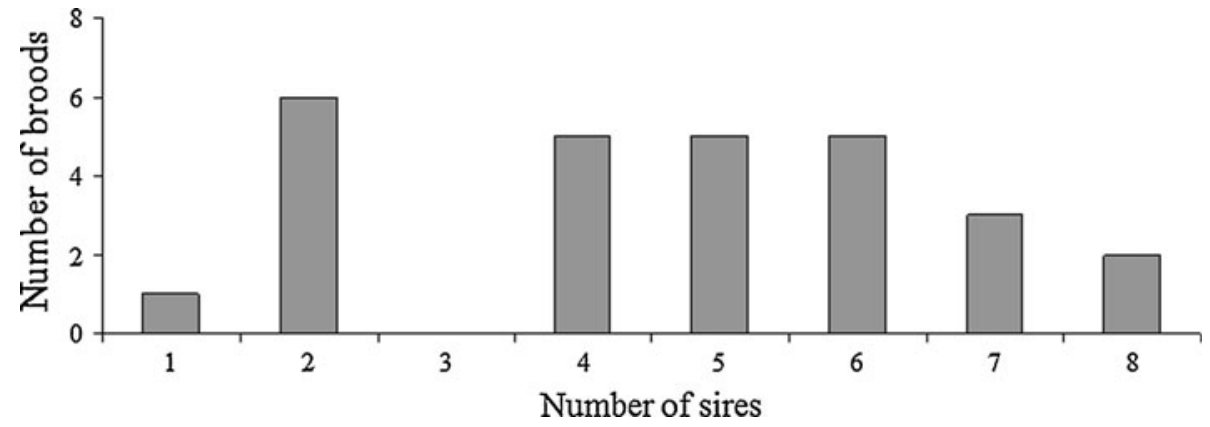

female sperm storage in $C$. aggregata is temporally longer (ca. 25 weeks; Wiebe 1968) than in E. jacksoni and E. lateralis (courtship behaviors last until 1 month before fertilization of eggs; Froeschke et al. 2007). Because of this prolonged sperm storage, disproportionately greater quantities of sperm may be necessary for paternity assurance in $C$. aggregata than in E. jacksoni and E. lateralis.
Accordingly, testis sizes of $C$. aggregata average much larger (relative to body size) than those of E. jacksoni and E. lateralis (Wiebe 1968; Froeschke et al. 2007). In C. aggregata, males also mature earlier, grow more slowly, and die younger than females, but not so in E. jacksoni and E. lateralis (Warner and Harlan 1982). All of these differences point toward a higher intensity of sperm 
Fig. 2 Estimated distribution of paternity within each brood. Gray and black segments of the bars represent the contributions of different sires, $n$ is number of progeny in the brood

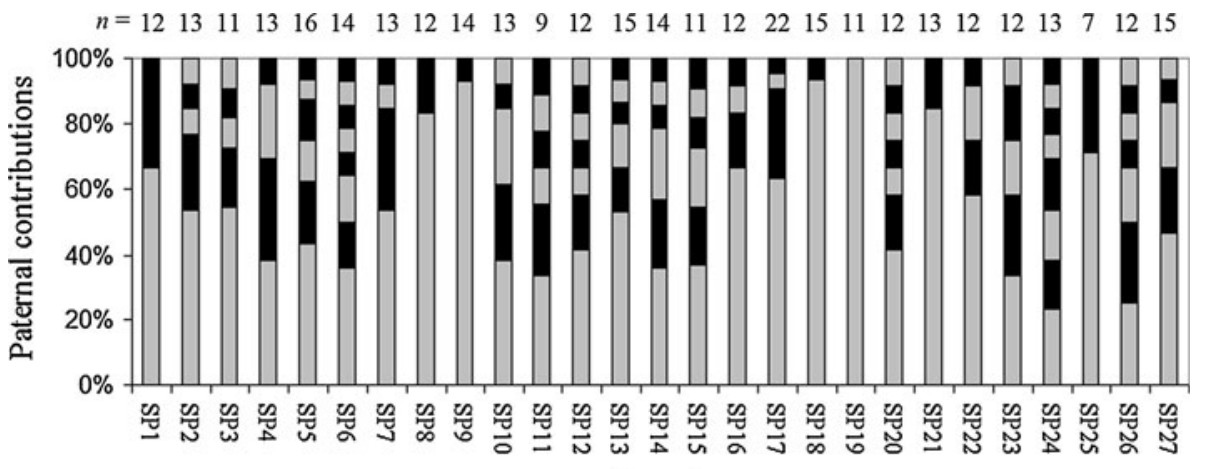

Brood competition in $C$. aggregata than in the other embiotocids (Stockley et al. 1997), which in turn may be related also to this species' exceptionally high degree of multiple paternity.

The high incidences of multiple paternity in surfperches indicate high levels of female promiscuity. Male embiotocids make no contribution to offspring production except for sperm, so direct benefits to females are unlikely to play an important role. It is still unclear whether the sperm form a significant nutritive source for the developing embryos (Dobbs 1975; Gardiner 1978c). However, if sperm is used as nutrient, the possible nutritive role of sperm may be a mild direct benefit of female multiple mating. Females of C. aggregata actively participate in mating activity, initiating and displaying reproductive behaviors that are similar to males (Shaw and Allen 1977). In E. jacksoni, females appear to exercise the primary selection of mates, because males perform courtship rituals within the full view of many females and the females then choose particular mates (Froeschke et al. 2007). Thus, "convenience polyandry" (Thornhill and Alcock 1983), which is an explanation for species where multiple mating incurs costs to females without obvious benefits, seems not to be a reasonable explanation for the high degree of multiple paternity in surfperches. Instead, multiple paternity in surfperch broods may reflect an evolutionary response to some form of indirect benefits to females of multiple mating.

Zeh and Zeh (2001) have suggested that polyandry for incompatibility avoidance is likely to be of greater importance for viviparous females than for females who lay eggs. Considering the advanced viviparous reproductive mode of surfperches, polyandry for the avoidance of genetic incompatibility may play an important role in the evolution of multiple mating. Embiotocids are conspicuous among viviparous teleosts because of their long gestational period, their minor quantity of yolk and, consequently, the almost complete dependency of their embryos on maternal nutrients supplied during gestation (deVlaming et al. 1983). In addition to nutrient supply, physiological and immunological interactions between fetus and mother are also reported in surfperches (Nakamura et al. 2006, 2009). Such intimate maternal-fetal interactions may make female surfperches particularly vulnerable to genetic incompatibility. Thus, by mating multiple times, a female surfperch may have the potential to utilize post-copulatory mechanisms to avoid the genetic-incompatibility threat. Furthermore, unlike many other marine fish, surfperches lack free-swimming pelagic larvae and both young and adults have low dispersal capabilities, which may increase the risk of mating with close relatives. Thus, the high degree of polyandry in surfperches might also be a mechanism for inbreeding avoidance, which can also be interpreted as a special case of polyandry for the avoidance of genetic incompatibility (Tregenza and Wedell 2000).

Sperm storage by females may also be responsible for the high degree of multiple paternity detected in C. aggregata. Thus, it should be interesting to compare the degree of polyandry in surfperches vis-à-vis oviparous species with prolonged sperm storage. Multiple paternity has been investigated in oviparous species of amphibians (Adams et al. 2005) and reptiles (Pearse et al. 2001; Uller and Olsson 2008) with prolonged sperm storage. However, the levels of multiple paternity in these oviparous species are lower than those observed in surfperches, thus implying that polyandry for incompatibility avoidance may be of greater importance for viviparous than for oviparous females. Considering that female surfperches can store viable sperm for long periods, we propose that the sperm storage phenomenon may have promoted the evolution of post-copulatory mechanisms that in effect enable females to assess their genetic compatibilities with multiple mates.

The key element for this hypothesis relating reproductive mode to genetic benefits is the degree to which embryological development involves maternal-fetal physiological interactions (Zeh and Zeh 2000, 2001). Viviparity (and "ovoviviparity") is developed to varying degrees in different families of teleost fishes (Wourms 1981). At one extreme are primitively viviparous species (such as members of the Sebastidae) in which the embryos are numerous, eggs have sufficient yolk for embryo nourishment, and 
offspring are born while still in a very immature state. Intermediate are fishes (such as species in the Poeciliidae) in which fairly large yolk sacs remain available to the embryos but the latter are retained in the ovary until they have reached an advanced stage that is nearly ready for swimming and feeding. At another extreme are members of the Embiotocidae in which the yolk sac is greatly reduced and the young are retained within the ovary until the embryos reach an advanced stage of development. Indeed, male Dwarf Surfperches, Micrometrus minimus, are sexually mature and ready for reproduction at birth (Warner and Harlan 1982). A comparison of the degrees of polyandry in these various teleost families should be useful for testing the genetic benefits/reproductive-mode hypothesis. Indeed, genetic estimates of levels of multiple paternity already have been conducted on natural populations representing several species in these families, and in general, the degree of multiple paternity proved to be higher in surfperches than in members of the Sebastidae and Poeciliidae (reviewed in Avise and Liu 2010). This observation is broadly consistent with predictions of the genetic benefits/reproductive-mode hypothesis.

In addition to indirect genetic benefits to polyandrous females, mate encounter rates may also play a role for the high degree of multiple paternity in surfperches. Mate encounter rates are high in the embiotocid taxa studied because all three species breed in large aggregations (Wiebe 1968; Froeschke et al. 2007), thus increasing the opportunity for mate competition among males and active pre-copulatory female choice. C. aggregata is the most abundant embiotocid species and forms very large aggregations during spawning season (Eigenmann 1892; Wiebe 1968), which could be responsible for the very high incidence of multiple paternity observed. A positive correlation between rates of multiple paternity and rates of mate encounter were reported among natural populations of the poeciliid fish, Heterandria formosa (Soucy and Travis 2003). Furthermore, patterns of multiple paternity across reptilian taxa also indicate that the degree of multiple paternity is generally higher in species with higher frequencies of mate encounters (reviewed in Uller and Olsson 2008). To illustrate the relative role of mate encounter frequency in polyandrous female surfperches, it could be interesting to quantify the degree of multiple paternity in closely related species with low population density, such as the Tule Perch, Hysterocarpus traskii.

In addition to the high degree of multiple paternity in C. aggregata, we detected strongly skewed distributions of fertilization success among the multiple sires of particular single broods, further suggesting that sperm competition and/or cryptic female choice might be important for postcopulatory paternity biasing in this species. Based on a fair-raffle process in sperm competition games (Parker
1990), a positive correlation between brood size and number of sires is anticipated. However, we detected no correlation between number of sires and brood size in C. aggregata, thus further implying that post-copulatory mechanisms inside the female could indeed play an important role in determining paternity. The results from this study differ from that of Darling et al. (1980), in which the polyandrous females appeared to be larger and carried more embryos. The apparent discrepancy between the two studies may merely reflect, however, a difference in the power of the genetic markers used to detect multiple paternity. Reproductive skew among males was also detected in both E. jacksoni and E. lateralis, but, as in C. aggregata, no correlation between brood size and number of sires was evident in these species (Reisser et al. 2009). These strikingly similar genetic results for three surfperch species indicate that cryptic female choice might be important as a post-copulatory mechanism that potentially could bias paternity toward males of high genetic quality. In fact, however, sperm competition and cryptic female choice are not mutually exclusive and are particularly difficult to distinguish (Eberhard 1998; Birkhead and Pizzari 2002). Thus, perhaps we might hypothesize that "female-mediated sperm competition" plays an important role in the post-copulatory paternity biasing in surfperches. To fully address the sperm competition hypothesis, a follow-up experiment is needed. It could be interesting to study the incidence of female multiple mating by analyzing the sperm stored by females and then compare results to those from the analysis of embryos.

Acknowledgments We thank A. Tatarenkov for technical assistance, A. Tatarenkov, R. Byrne and two anonymous reviewers for their helpful comments. This work was supported by the University of California, Irvine.

Open Access This article is distributed under the terms of the Creative Commons Attribution Noncommercial License which permits any noncommercial use, distribution, and reproduction in any medium, provided the original author(s) and source are credited.

\section{References}

Adams EM, Jones AG, Arnold SJ (2005) Multiple paternity in a natural population of a salamander with long-term sperm storage. Mol Ecol 14:1803-1810

Avise JC, Liu JX (2010) Multiple mating and its relationship to alternative modes of gestation in male-pregnant versus femalepregnant fish species. Proc Natl Acad Sci USA 107:1891518920

Avise JC, Jones AG, Walker D et al (2002) Genetic mating systems and reproductive natural histories of fishes: lessons for ecology and evolution. Annu Rev Genet 36:19-45

Baltz DM (1984) Life history variation among female surfperches (Perciformes: Embiotocidae). Environ Biol Fish 10:159-171 
Birkhead TR, Møller AP (1993) Sexual selection and the temporal separation of reproductive events: sperm storage data from reptiles, birds and mammals. Biol J Linn Soc 50:295-311

Birkhead TR, Møller AP (1998) Sperm competition and sexual selection. Academic Press, London

Birkhead TR, Pizzari T (2002) Postcopulatory sexual selection. Nat Rev Genet 3:262-273

Boutin-Ganache I, Raposo M, Raymond M, Deschepper CF (2001) M13-tailed primers improve the readability and usability of microsatellite analysis performed with two different allele-sizing methods. Biotechniques 31:24-28

Curtsinger JW (1991) Sperm competition and the evolution of multiple mating. Am Nat 138:93-102

Darling JDS, Noble ML, Shaw E (1980) Reproductive strategies in the surfperches. I. Multiple insemination in natural populations of the shiner perch, Cymatogaster aggregata. Evolution 34:271-277

DeMartini EE (1969) A correlative study of the ecology and comparative feeding mechanism morphology of the Embiotocidae (surf-fishes) as evidence of the family's adaptive radiation into available ecological niches. Wasmann J Biol 27:177-247

DeMartini EE (1988) Size-assortative courtship and competition in two Embiotocid fishes. Copeia 2:336-344

deVlaming V, Baltz D, Anderson S, Fitzgerald R, Delahunty G, Barkley M (1983) Aspects of embryo nutrition and excretion among viviparous embiotocid teleosts: Potential endocrine involvements. Comp Biochem Physiol A 76:189-198

Dobbs GH (1975) Scanning electron microscopy of intraovarian embryos of the viviparous teleost, Micrometrus minimus (Gibbons), (Perciformes: Embiotocidae). J Fish Biol 7:209-214

Dodds KG, Tate ML, McEwan JC, Crawford AM (1996) Exclusion probabilities for pedigree testing farm animals. Theor Appl Genet 92:966-975

Eberhard WG (1998) Female roles in sperm competition. In: Birkhead TR, Møller AP (eds) Sperm competition and sexual selection. Academic Press, London, pp 91-116

Eigenmann CH (1892) Cymatogaster aggregatus Gibbons; a contribution to the ontogeny of viviparous fishes. Bull United States Fish Comm 12:401-478

Froeschke B, Allen LG, Pondella DF II (2007) Life history and courtship behavior of black perch, Embiotoca jacksoni (Teleostomi: Embiotocidae), from Southern California. Pac Sci 61:521-531

Gardiner DM (1978a) The origin and fate of spermatophores in the viviparous teleost Cymatogaster aggregata (Perciformes: Embiotocidae). J Morphol 155:157-172

Gardiner DM (1978b) Cyclic changes in fine structure of the epithelium lining of the ovary of the viviparous teleost: Cymatogaster aggregata (Perciformes: Embiotocidae). J Morphol 156:367-380

Gardiner DM (1978c) Utilization of extracellular glucose by spermatozoa of two viviparous fishes. Comp Biochem Physiol A 59:165-168

Griffith SC, Owens IP, Thuman KA (2002) Extra pair paternity in birds: a review of interspecific variation and adaptive function. Mol Ecol 11:2195-2212

Guo SW, Thompson EA (1992) Performing the exact test of HardyWeinberg proportion for multiple alleles. Biometrics 48:361-372

Hamilton MB, Pincus EL, Di Fiore A, Fleischer RC (1999) Universal linker and ligation procedures for construction of genomic DNA libraries enriched for microsatellites. Biotechniques 27:500-507

Hauswaldt JS, Glenn TC (2003) Microsatellite DNA loci from the Diamondback terrapin (Malaclemys terrapin). Mol Ecol Notes 3:174-176
Hubbs CL (1917) The breeding habits of the viviparous perch, Cymatogaster. Copeia 47:72-74

Jennions MD, Petrie M (2000) Why do females mate multiply? A review of the genetic benefits. Biol Rev 75:21-64

Jones AG (2005) Gerud 2.0: a computer program for the reconstruction of parental genotypes from half-sib progeny arrays with known or unknown parents. Mol Ecol Notes 5:708-711

Jones OR, Wang J (2010) Colony: a program for parentage and sibship inference from multilocus genotype data. Mol Ecol Res 10:551-555

Keller L, Reeve HK (1995) Why do females mate with multiple males? The sexually selected sperm hypothesis. Adv Stud Behav 24:291-315

Milligan BG (1998) Total DNA isolation. In: Hoelzel AR (ed) Molecular genetic analysis of populations: a practical approach. Oxford University Press, Oxford, pp 28-64

Nakamura O, Kudo R, Aoki H, Watanabe T (2006) IgM secretion and absorption in the materno-fetal interface of a viviparous teleost, Neoditrema ransonneti (Perciformes; Embiotocidae). Dev Comp Immunol 30:493-502

Nakamura O, Nozawa Y, Saito E, Ikeda D, Tsutsui S (2009) An alpha-1-acid glycoprotein-like protein as a major component of the ovarian cavity fluid of viviparous fish, Neoditrema ransonnetii (Perciformes, Embiotocidae). Comp Biochem Physiol A 153:222-229

Nonacs P (2000) Measuring and using skew in the study of social behavior and evolution. Am Nat 156:577-589

Parker GA (1990) Sperm competition games—raffles and role. Proc Roy Soc B 242:120-126

Parker GA (1998) Sperm competition and the evolution of ejaculates: towards a theory base. In: Birkhead TR, Moller AP (eds) Sperm competition and sexual selection. Academic Press, London

Pearse DE, Janzen FJ, Avise JC (2001) Genetic markers substantiate long-term storage and utilization of sperm by female painted turtles. Heredity 86:378-384

Reisser CMO, Beldade R, Bernardi G (2009) Multiple paternity and competition in sympatric congeneric reef fishes, Embiotoca jacksoni and E. lateralis. Mol Ecol 18:1504-1510

Schneider S, Roessli D, Excoffier L (2000) Arlequin: a software for population genetics data analysis. Ver. 2.0. Genetics and Biometry Laboratory, Department of Anthropology, University of Geneva

Seutin G, White BN, Boag PT (1991) Preservation of avian blood and tissue samples for DNA analyses. Can J Zool 69:82-90

Shaw E (1971) Evidence of sexual maturation in young adult shiner perch, Cymatogaster aggregata Gibbons (Perciformes, Embiotocidae). Am Mus Novit 2479:1-10

Shaw E, Allen J (1977) Reproductive behavior in the female shiner perch, Cymatogaster aggregata. Mar Biol 40:81-86

Simmons LW (2005) The evolution of polyandry: sperm competition, sperm selection, and offspring viability. Annu Rev Ecol Evol Syst 36:125-146

Soucy S, Travis J (2003) Multiple paternity and population genetic structure in natural populations of the poeciliid fish, Heterandria formosa. J Evol Biol 16:1328-1336

Soulsbury CD (2010) Genetic patterns of paternity and testes size in mammals. Plos One 5(3):e9581

Stockley P (2003) Female multiple mating behaviour, early reproductive failure and litter size variation in mammals. Proc Roy Soc B 270:271-278

Stockley P, Gage MJG, Parker GA, Møller AP (1997) Sperm competition in fishes: the evolution of testis size and ejaculate characteristics. Am Nat 149:933-954

Tarp FH (1952) A revision of the family Embiotocidae (the surfperches). Fish Bull Calif Dep Fish Game 88:1-99 
Thornhill R, Alcock J (1983) The evolution of insect mating systems. Harvard University Press, Cambridge

Tregenza T, Wedell N (2000) Genetic compatibility, mate choice and patterns of parentage: invited review. Mol Ecol 9:1013-1027

Turner CL (1938) Histological and cytological changes in the ovary of Cymatogaster aggregatus during gestation. J Morphol 62:351-373

Uller T, Olsson M (2008) Multiple paternity in reptiles: patterns and process. Mol Ecol 17:2566-2580

Van Oosterhout C, Hutchinson WF, Wills DPM, Shipley P (2004) Micro-checker: software for identifying and correcting genotyping errors in microsatellite data. Mol Ecol Notes 4:535-538

Wang J (2004) Sibship reconstruction from genetic data with typing errors. Genetics 166:1963-1979

Wang J, Santure AW (2009) Parentage and sibship inference from multilocus genotype data under polygamy. Genetics 181:15791594

Warner RR, Harlan RK (1982) Sperm competition and sperm storage as determinants of sexual dimorphism in the dwarf surfperch, Micrometrus minimus. Evolution 36:44-55
Wiebe JP (1968) The reproductive cycle of the viviparous seaperch, Cymatogaster aggregata Gibbons. Can J Zool 46:1221-1234

Wourms JP (1981) Viviparity: the maternal-fetal relationship in fishes. Am Zool 21:473-515

Yasui Y (1998) The 'genetic benefits' of female multiple mating reconsidered. Trends Ecol Evol 13:246-250

Yasui Y (2001) Female multiple mating as a genetic bet-hedging strategy when mate choice criteria are unreliable. Ecol Res 16:605-616

Zeh JA, Zeh DW (1996) The evolution of polyandry I: intragenomic conflict and genetic incompatibility. Proc Roy Soc B 263:1711-1717

Zeh JA, Zeh DW (1997) The evolution of polyandry II: postcopulatory defenses against genetic incompatibility. Proc Roy Soc B 264:69-75

Zeh JA, Zeh DW (2000) Reproductive mode and speciation: the viviparity-driven conflict hypothesis. BioEssays 22:938-946

Zeh JA, Zeh DW (2001) Reproductive mode and the genetic benefits of polyandry. Anim Behav 61:1051-1063 